\title{
De El capital de Marx a la democracia republicana: en el segundo centenario de su nacimiento*
}

FÉLIX JiMÉNEZ

Este texto se divide en tres partes. Primero, describiré mi encuentro con los escritos de Marx y adónde me condujo. Segundo, mencionaré algunas críticas a sus planteamientos más importantes. Por último, concluiré mencionando cuál sería el contenido de un ideario político-filosófico partiendo de un Marx partidario de la democracia con emancipación.

\section{MI ENCUENTRO}

Debo decir que empecé a leer a Marx desde muy joven y que fui impactado por sus Manuscritos de 1844 y por sus poemas a Jenny von Westphalen compuestos antes de su casamiento de 1843: "Amor es Jenny, Jenny es el nombre del amor», decía Marx; "Toma estos cantos / en los que todo es melodía, / alberga este amor que, humilde, a tus pies se postra».

Después me topé con Marx y su concepto del hombre, obra escrita por Erich Fromm inspirada en los Manuscritos, y en el que señala que, según Marx, el espíritu de independencia caracteriza la naturaleza del hombre. Este libro de Fromm termina con la interesante entrevista a Marx que le hace su hija Eleanor. Marx no era marxista y nada humano le era ajeno, según dicha entrevista.

\footnotetext{
* Un resumen de este texto fue leído el 21 de mayo en el evento "El fantasma de Marx: conversatorios sobre la vigencia de sus ideas; en conmemoración del bicentenario de su nacimiento 1818-2018". El conversatorio fue organizado por el Instituto Goethe y el Centro de Estudios Filosóficos de la PUCP.

** Economista, Ph. D. Profesor principal de la PUCP.
} 
Después leí otros libros, varios de ellos escritos con Federico Engels como: La sagrada Familia (o crítica de la crítica critica), La ideología alemana, El Manifiesto Comunista, y Salario, precio y ganancia, que fue el discurso pronunciado en 1865 criticando a John Weston de la AIT.

Debo decir, sin embargo, que empecé una lectura sistemática de El Capital, sus Borradores (Grundrisse) y otros trabajos de Marx, recién a comienzos de la década de 1970 en el Centro de Estudios e Investigaciones Sociales que dirigía Aníbal Quijano y en el que también participaba Guillermo Rochabrún. Luego continué con este tipo de lectura en México.

En esa misma década, cuando hacía mi maestría en Economía en El Colegio de México, conocí a Carlos Roces y a su padre Wenceslao, el que tradujo El Capital y que publicó el Fondo de Cultura Económica. Carlos fue mi profesor de Teoría Económica y después mi asesor de tesis. Me gradué de magíster en Economía con la tesis titulada Marx y Wicksell: dos concepciones sobre el valor, los precios y la distribución.

Debo mencionar, por último, a manera de homenaje, a José Arico (Pancho, para sus amigos) — que trabajaba en la Editorial Siglo XXI de México—, autor del libro Marx y América Latina. Él tuvo la paciencia de leer algunos capítulos de mi tesis y fui favorecido con una vasta bibliografía inédita en español que él solía proporcionarme.

Varias lecturas y relecturas posteriores como las de los autores Polanyi, Keynes, Kaldor, Kalecki, Sraffa, Skidelsky, Acemoglu, Jeffrey Williamson; mis relecturas de Smith y Ricardo, y de varios teóricos del subdesarrollo y la dependencia, de Giovanni Arrighi —el autor del importante libro Adam Smith en Pekin. Orígenes y fundamentos del siglo XXI-, de Todorov y de algunos teóricos de la escuela de Cambridge sobre el Republicanismo (Pocock, Skinner y Petit), hicieron que Marx pasara a un segundo plano en mis reflexiones teóricas y políticas.

No obstante lo anterior, leyendo el libro de Derrida (2012) —cuyo título inspira este conversatorio - caigo en la cuenta que efectivamente hay un «Un fantasma (que) no muere jamás, (que) siempre está por aparecer y por (re)aparecer» (p. 115). Este es el fantasma del Marx crítico y del ciudadano en acción que buscaba un mundo mejor y más justo. Es el fantasma capaz de autocrítica y abierto — dice Derrida-«a su propia transformación, a su reevaluación y a su auto reinterpretación» (p. 102).

Con la audacia que me genera esta afirmación de Derrida intentaré primero pergeñar una criticas al pensamiento de Marx y luego, también siguiendo las sugerencias de Derrida, propondré el contenido de un ideario político alternativo. No aludiré en absoluto al heterogéneo marxismo, recordando que el propio Marx se declaraba «no ser un marxista». 


\section{MIS CRÍTICAS}

1) Para Marx, el capital es una relación social de explotación de la clase obrera por la clase capitalista, de valorización en el sentido de extracción de la mayor cantidad posible de excedente. «El capital produce esencialmente capital, y lo hace así en tanto que produce valor excedente» (1967, vol. III, p. 880).

De esta formidable explicación de la explotación de los trabajadores, Marx pasa a afirmar que el capital y el capitalismo, son el resultado inexorable del desarrollo de las fuerzas productivas. «No son los artículos elaborados — dice Marx-, sino cómo fueron elaborados y con qué instrumentos, lo que nos permite distinguir diferentes épocas económicas. Los instrumentos de trabajo no solamente ofrecen un estándar del grado de desarrollo que el trabajo humano logra, sino que también son indicadores de las condiciones sociales por las que el trabajo es llevado a cabo» (1967, vol. I, p. 180).

Hay, por consiguiente,—según Marx — una ley inexorable en la historia, una «fatalidad histórica», que condujo al capitalismo y que nos conducirá al socialismo ${ }^{1}$.

La contradicción entre el desarrollo de las fuerzas productivas y las relaciones de producción anuncia, en determinado momento de la historia, el cambio hacia un nuevo modo de producción. El ser social determina la conciencia.

Este es un determinismo ciertamente criticable. Pero Marx también es un voluntarista. Hay un curso inexorable que toma la historia. Si la clase - que no tiene nada que perder, solo sus cadenas-actúa provocando cambios que se ajustan a este curso de la historia, entonces «Ahora — como dice Todorov- le toca a la consciencia determinar la existencia» (p. 46) ${ }^{2}$.

Hay que anotar, además, que la lucha de clases es, para Marx, la única forma de interacción social que caracteriza la historia de la humanidad ${ }^{3}$. La clase que se apodera del poder lo utiliza para explotar a la otra. En esta concepción — como

1 Como señala Todorov (2012), Marx desarrolla su pensamiento «en una época en la que en general se admiran los logros de la ciencia, que en esos momentos ilustra la Revolución industrial. De ahí surgirá una doctrina, el cientificismo, que no debe confundirse con la ciencia, y que incluso se opone a su espíritu. El cientificismo afirma que el mundo puede conocerse íntegramente, y que por lo tanto puede transformarse en función de un ideal. Y que este ideal no se elige libremente, sino que deriva del propio conocimiento» (p. 44). 2 Se dice que «que la actividad humana está totalmente sometida a leyes sobre las que los hombres no tienen la menor influencia. Sin embargo, el marxismo no es solo una doctrina determinista, sino que es a la vez de un voluntarismo intransigente. La articulación de estas dos características, en apariencia contradictorias, queda explicitada en el famoso dogma marxista que afirma que "la existencia determina la consciencia». La consciencia, y por lo tanto la voluntad de los individuos, está segura de actuar en el sentido que prevén las leyes de la historia, porque es producto de ella. El querer secunda necesariamente al ser» (Todorov, p. 46). 3 En el Manifiesto del Partido Comunista se lee: «Las proposiciones teóricas de los comunistas no se fundan de ningún modo en ideas y principios inventados o descubiertos por tal o cual reformador del mundo. No son sino la expresión de conjunto de las condiciones reales de una lucha de clases existente, de un movimiento histórico en constante evolución». Véase Marx y Engels (2000, p. 50). 
dice Todorov—, "Nada es común a todos los miembros de una sociedad. Todo forma parte de uno u otro bando en lucha. No hay ninguna categoría universal, ni la moral, ni la justicia, ni las ideas, ni la civilización. Ninguna religión, ninguna tradición (como la familia, incluso la propiedad privada) escapa a su pertenencia a una clase» (p. 44) ${ }^{4}$.

En el socialismo, desaparecerá la clase capitalista como resultado de una revolución social conducida por la clase obrera. Es imposible, sin embargo, que este tipo de revolución ocurra sin derramamiento de sangre ${ }^{56}$.

2) Su determinismo le llevó a afirmar que «los países pobres tienen en los países ricos el espejo de su propio porvenir». Los países pobres tienen que pasar por esta «fatalidad histórica». No importa que su teoría elaborada corresponda a una economía con una estructura productiva distinta a la que tienen los países pobres (que conduce a patrones de crecimiento y acumulación distintos). Por eso no sorprende que Marx afirme, refiriéndose a la dominación de Inglaterra sobre la India, lo siguiente:

Bien es verdad que al realizar una revolución social en el Indostán, Inglaterra actuaba bajo el impulso de los intereses más mezquinos, dando pruebas de verdadera estupidez en la forma de imponer esos intereses. Pero no se trata de eso. De lo que se trata es de saber si la humanidad puede cumplir su misión sin una revolución a fondo en el estado social de Asia. Si no puede, entonces, y a pesar de todos sus crímenes, Inglaterra fue el instrumento inconsciente de la historia al realizar dicha revolución. En tal caso, por penoso que sea para nuestros sentimientos personales el espectáculo de un viejo mundo que se derrumba, desde el punto de vista de la historia tenemos pleno derecho a exclamar con Goethe: ¿Quién lamenta los estragos / Si los frutos son placeres? / ¿No aplastó miles de seres / Tamerlán en su reinado?» (Marx, 1853) ${ }^{7}$.

4 Como bien se sabe Antonio Gramsci introduce el concepto de hegemonía que se impone sobre el de lucha de clases. Así, para este marxista italiano, los procesos de emancipación podían ser liderados por las «organizaciones» con hegemonía moral y política.

5 Pero, como señala Todorov (2012), «El fin previsto por la «ciencia» marxista es que desaparezcan todas las diferencias entre grupos humanos, porque consideran que toda diferencia es una fuente de conflictos, y en último término una lucha a muerte. Por eso es preciso abolir la propiedad privada y concentrar todos los medios de producción en manos del Estado. Se eliminará a los que ofrezcan resistencia, así como a la burguesía, cuyos intereses van en sentido contrario» (p. 45).

6 «De todas formas, la transformación de la sociedad que contempla el Manifiesto es tan radical —supresión de la propiedad privada y desaparición de las clases- que es inconcebible que pueda ponerse en práctica sin derramar sangre» (Todorov, 2012, p. 46).

Según Immanuel Wallerstein, «Marx siempre estuvo dispuesto a lidiar con la realidad del mundo, no como muchos otros que dogmáticamente impusieron sus puntos de vista. Marx cambió de parecer a menudo» (véase Musto, 2018). En efecto, en 1881, dos ańos antes de su muerte, en carta a Vera Zasúlich, Marx afirma que se ha convencido de que la comuna rural «es el punto de apoyo de la regeneración social en Rusia, más para que pueda funcionar como tal será preciso eliminar primeramente las influencias deletéreas que la acosan por todas partes y a continuación asegurarle las condiciones normales para un desarrollo 
3) Marx escribe en ese largo siglo XIX (que va de 1789 a 1914), en los inicios de la segunda revolución industrial y en pleno apogeo del mercado autorregulado. Pero, para él no es el sistema de mercado autorregulado el que puso en riesgo a la sociedad en su conjunto y que condujo a una profunda degradación de los valores y las instituciones. La corrupción y el asalto político de los grandes poderes económicos, fueron parte de un proceso caracterizado por una conducta social y una práctica política que operaron en el sentido del deterioro de la sociedad. El presidente de Estados Unidos Rutherford Hayes de esa época (1876) decía con todo cinismo: «este gobierno es de las empresas, por las empresas y para las empresas» (López Arnal, 2003, p. 22).

Karl Polanyi (2003) sostiene que un mercado que se regula a sí mismo «no podía existir de forma duradera sin aniquilar la sustancia humana y la naturaleza de la sociedad, sin destruir al hombre y sin transformar su ecosistema en un desierto» (p. 26).

Lo ocurrido en el siglo XIX condujo a «una de las crisis más profundas que han existido en la historia de la humanidad». Los contramovimientos de defensa amortiguaron la acción de ese mecanismo autodestructivo, pero desembocaron, por una parte, en el denominado socialismo, y por otra, en el fascismo y el nacionalsocialismo.

Para Polanyi, la historia, es la historia de la autodefensa de la sociedad frente a la utopía del mercado autorregulado, la historia del proteccionismo frente a la idea de mercantilización de todas las cosas. "La civilización del siglo XIX — dice Polanyi- no fue destruida por un ataque exterior o interior de los bárbaros; su vitalidad no se vio minada ni por las devastaciones de la Primera Guerra Mundial, ni por la rebelión de un proletariado socialista o de una pequeña burguesía fascista. Su fracaso no fue consecuencia de supuestas leyes de la economía, tales como la baja tendencial de la tasa de ganancias, la del subconsumo o la de la superproducción. Su desintegración fue más bien el resultado de un conjunto de causas muy diferentes: las medidas adoptadas por la sociedad para no verse aniquilada por la acción del mercado autorregulador» (p. 391).

\section{EL CONTENIDO DE UN NUEVO IDEARIO}

El pensamiento de Marx — dice Derrida— «Es heredero (del) espíritu de la Ilustración al que no hay que renunciar» y pide, a partir de él, asumir la responsabilidad de construir un nuevo ideario político-filosófico de transformación (2012, p. 102).

Pero, ¿cuál sería el contenido de este ideario, después de la impostura del socialismo real y en plena globalización del mercado autorregulado de los últimos treinta años? 
Este ideario se debería construir — según Derrida — «sin renunciar a un ideal de democracia y de emancipación, intentando, más bien, pensarlo y ponerlo en marcha de otra manera» (2012, pp. 104-105) .

A mi juicio, construir un ideario de «democracia con emancipación», implica recurrir al humanismo del joven Marx de los Manuscritos; recordar su militancia en la primera asociación política internacional denominada Fraternal Democrats fundada en Londres en 1845 (véase López Arnal, 2003, p. 5); partir de su reconocimiento a la importancia de la idea de una República Democrática cuando en 1864 le escribe a Abraham Lincoln felicitándolo por su reelección luego de haber derrotado a las fuerzas esclavistas del sur; recordar su republicanismo, es decir, al Marx que se despedía en muchas de sus cartas anteponiendo el adverbio «fraternalmente» a la firma (p. 6); al Marx al que, según propia confesión, "nada humano le era ajeno»; y, en fin, inspirarnos siempre en su undécima tesis sobre Feuerbach de 1845.

La tarea, entonces, sería reconstruir los fundamentos del «ideal de democracia con emancipación", mediante una relectura del pensamiento republicanista sobre la libertad, el mercado, la democracia y el Estado; de una relectura de los valores fundacionales de la tradición republicana, como son la emancipación social, el énfasis en lo público y la virtud cívica (Pocock, Dunn, Skinner, Pettit y Viroli).

El contenido de este nuevo ideario debe incluir, entonces:

1) La concepción republicada de la libertad como ausencia de dominación; y, no "como simple isonomía frente a la ley y ausencia de interferencia». Las personas no pueden ser libres si no disponen de condiciones materiales de existencia. Para garantizar esta libertad, según Polanyi, debe haber un diseño institucional o una regulación política-jurídica, y también económica?

Para el republicanismo, como nos recuerda Casassas, la vida social no es un espacio políticamente neutral; no es un espacio sin relaciones de poder, en donde los actores sociales se limitan a la firma de contratos, libre y voluntariamente (López Arnal, 2011, pp. 103-126). Por lo tanto, la libertad no es exógena a la vida social. Se alcanza y se mantiene por medios políticos, construyendo lo que Adam Smith denominaba cortafuegos con el fin de impedir la dominación social.

2) La concepción republicana del mercado. Reconocer que la economía de mercado no es necesariamente sinónimo de economía capitalista, ni de mercado autorregulado.

8 Derrida nos pide realizar «una transformación profunda, proyectada sobre un largo período, del derecho internacional, de sus conceptos y de su campo de intervención» que él llama «la nueva Internacional» (p. 98). 9 «Si un Estado está comprometido con el progreso de la causa de la libertad como no-dominación entre sus ciudadanos — dice Pettit—, no puede menos que adoptar una política que promueva la independencia socioeconómica» (1997, p. 210). 
Gran parte de la izquierda cometió el error de "cederle» la institución del mercado a la derecha liberal. El neoliberalismo exacerbó este prejuicio de la izquierda al contraponer el mercado al Estado y la economía a la política.

Tenemos que restituirle al mercado su carácter de institución social y su capacidad de mecanismo de inclusión social. Este papel del mercado, de acuerdo al pensamiento republicanista, se construye políticamente. El Estado tiene que eliminar las fuentes institucionales y sociales de poderes económicos que afectan a la libertad y a la democracia. Estos poderes no rinden cuentas a nadie y transforman las democracias en plutocracias.

3) Construir una democracia republicana. La globalización del mercado autorregulado y el rechazo a la intervención económica del Estado, desencadenó una crisis de ideologías y puso en evidencia las debilidades de la democracia. La lógica del poder se impuso en la política dañando severamente la esencia de la democracia: los partidos desprovistos de ideología se convirtieron solo en estructuras de poder. La «democracia» se reduce al momento de elegir a los representantes, pero cuando los grupos de poder privados asumen el control mediático de la sociedad, se anula en la práctica la libertad de los electores.

Se trata entonces de restituirle a la democracia la virtud civica: "piedra angular de la vida en común en una sociedad civil plural, diferenciada». Esta restitución debe ser acompañada del perfeccionamiento de los controles democráticos que permitan evitar, lo que Antonio Rivera llama, «la patológica oligarquización del Estado o la usurpación del espacio político por una minoría» (2008, pp. 193-201).

Nuevos mecanismos de control constitucional de los elegidos, el principio de rotación o de no reelección, y la limitación recíproca de los poderes, incluido el poder económico y mediático, harán posible el retorno de la política como lazo de conexión social; el retorno de la virtud cívica o del deber de participar en la esfera política.

4) Construir un Estado que asegure el ejercicio pleno de la libertad. Mientras el neoliberalismo combate el intervencionismo del Estado y postula su neutralidad económica, el republicanismo le otorga un papel promotor de la libertad y la democracia y no lo contrapone al mercado. El Estado republicano debe ejercer una tarea regulatoria para evitar la acumulación de poder económico y asegurar el ejercicio pleno de la libertad, dotando de condiciones materiales de existencia a todos los que carecen de ellas. También debe promover la virtud cívica y el ejercicio de la ciudadanía, e incorporar mecanismos constitucionales de evaluación y control de los gobernantes elegidos por el pueblo para impedir que gobiernen en función de los intereses de minorías económicas.

Debe, además, promover el desarrollo de mercados internos. La ausencia o poco desarrollo de estos mercados, es la otra cara de la perpetuación de la desigualdad 
y desarticulación del país. Cuando no hay mercados o estos están poco desarrollados — decimos parafraseando al Marx republicano_-, las poblaciones pobres y excluidas no llevan en el bolsillo su conexión con la sociedad. Todo ello nos debería llevar a recuperar la soberanía de los Estados Nacionales.

La Globalización del mercado autorregulado ha acentuado la miseria y exclusión social de centenares de millones de personas, convirtiéndose así en una seria amenaza no solo a su libertad, sino también a la autodeterminación soberana de muchos países del llamado tercer mundo. El modelo económico difundido con esta globalización ha acentuado en nuestro país el extractivismo político y económico. La economía funciona con impulsos externos y con actividades primarias que no respetan la ecología y, por lo tanto, los derechos de los pueblos indígenas.

La libertad y la ciudadanía republicanas son incompatibles con las relaciones de dominación y la dependencia material. La desigualdad resultante de la constitución de poderes económicos, atenta contra la libertad y la democracia. De la misma manera, la soberanía de un Estado es incompatible con la dependencia económica de poderes extranjeros. Sin el uso autónomo de sus recursos naturales para el desarrollo nacional, no hay ejercicio pleno de su soberanía.

La convivencia democrática en el concierto internacional, en condiciones de igualdad, y con una economía abierta, supone la existencia de Estados soberanos con condiciones materiales que les permite interactuar libremente.

Entonces, en consonancia con el pensamiento republicano, el carácter nacional de la transformación que requiere nuestro país, tiene que ser una reacción de autodeterminación nacional frente a las presiones de la globalización para desmantelar todos los estándares regulatorios (abaratamiento del costo del trabajo y flexibilización laboral, liberalización total del comercio y de los flujos de capital internacional, estímulos tributarios al capital extranjero, etc.). La autodeterminación nacional, el ejercicio soberano de las políticas económicas y el fortalecimiento de la democracia son incompatibles con esta globalización que especializa y no diversifica el aparato productivo del país.

\section{REFERENCIAS BIBLIOGRÁFICAS}

Derrida, Jacques (2012). Espectros de Marx. El estado de la deuda, el trabajo del duelo y la nueva internacional. Quinta edición. Madrid: Trotta.

López Arnal, Salvador (2003). Entrevista político-filosófica a Antoni Domenech, catedrático de Ética y Filosofía Política de la Universidad de Barcelona. Rebelión, junio/julio.

López Arnal, Salvador (2011). Entrevista a David Casassas sobre Adam Smith y La ciudad en llamas. SinPermiso, 9, pp. 103-126.

Marx, Karl (1853). La dominación británica en la India. Disponible en https://www.marxists.org/ espanol/m-e/1850s/25-vi-1853.htm 
Marx, Karl (1967[1887]). Capital: A Critique of Political Economy. Volume I: The Process of Capitalist Production. Nueva York, NY: International Publishers.

Marx, Karl (1967[1894]). Capital: A Critique of Political Economy. Volume III: The Process of Capitalist Production as a Whole. Nueva York, NY: International Publishers.

Marx, Karl y Frederic Engels (2000). El Manifiesto Comunista. Ediciones elaleph.com. Disponible en https://sociologia1 unpsjb.files.wordpress.com/2008/03/marx-manifiesto-comunista.pdf

Musto, Marcello (2018). ¡Leer a Marx!: una conversación con Immanuel Wallerstein. En Sin Permiso, del 5 de mayo de 2018. Disponible en http://www.sinpermiso.info/textos/leer-a-karl-marx-una-conversacion-con-immanuel-wallerstein

Pettit, Philip (1997). Republicanism. Oxford: Clarendon Press.

Polanyi, Karl (2003). La gran transformación. México: Fondo de Cultura Económica.

Rivera, Antonio (2008). Apología del republicanismo democrático. Res publica, 20, pp. 193-201. Todorov, Tzvetan (2012). Los enemigos intimos de la democracia. Barcelona: Galaxia Gutenberg.

Documento recibido el 1 de junio de 2018 y aprobado el 31 de julio de 2018 